\title{
Vegetative Propagation of American Beech Resistant to Beech Bark Disease
}

\author{
Marianela Ramirez and Marek J. Krasowski \\ Faculty of Forestry and Environmental Management, University of \\ New Brunswick, P.O. Box 44555, 28 Dineen Drive, Fredericton, NB E3B \\ 6C2, Canada \\ Judy A. Loo ${ }^{1}$ \\ Natural Resources Canada, Canadian Forest Service-Atlantic Forestry \\ Centre, P.O. Box 4000, Fredericton, NB E3B 5P7, Canada
}

Additional index words. Fagus grandifolia, grafting, indolebutyric acid, in vitro culture, micropropagation, Nectria coccinea var faginata, rootstock, scion, sterilization, tissue culture

\begin{abstract}
The objective of this study was to develop vegetative propagation techniquesusing tissue culture and grafting-for American beech (Fagus grandifolia) resistant to beech bark disease. Resterilizing the buds after excising bud scales reduced contamination of in vitro cultures derived from dormant buds. Application of a 7-day dark treatment before transferring shoots to the rooting medium improved rooting success. Plantlets gradually acclimatized to nonsterile growth conditions and set buds but failed to survive the dormant period. The application of 6-benzyladenine enhanced sprouting from roots collected from mature trees, but the excised shoots rooted poorly in vitro despite low contamination. Success of grafting scions from mature trees varied among genotypes and differed each year (30\% in 2003, $12 \%$ in 2004, and $18 \%$ in 2005). Applying the growth hormone indole butyric acid to the scion before joining it to the rootstock did not increase grafting success. Survival of grafts was independent of rootstock age $(1$ or 2 years old). Grafting success increased when scion diameter was slightly larger than rootstock diameter. The rooting of sucker cuttings was successful for only one genotype. Critical steps, in which most failures in the propagation of American beech occur, are identified.
\end{abstract}

American beech (Fagus grandifolia) trees in the northeastern parts of its range have been devastated by beech bark disease (BBD), an introduced insect-fungus disease complex incited by an initial infestation by the scale insect, Cryptococcus fagisuga Lind., followed by infection with one of the Nectria fungi, primarily Nectria coccinea var. faginata Lohman, Watson \& Ayers. The disease has dramatically decreased the commercial value of many forest stands that have a significant beech component and has reduced their ecologic importance (Houston, 1980).

In stands severely affected by BBD, some symptom-free trees exist in low frequencies. These apparently disease-free trees often occur in groups and are closely related (Houston and Houston, 1994). It is thought

\footnotetext{
Received for publication 2 June 2006. Accepted for publication 10 Aug. 2006.

Financial support for this study provided by Parks Canada, the Fundy Model Forest, Natural Resources Canada-Canadian Forest Service (NRCanCFS), the National Science and Research Council of Canada, and the Faculty of Forestry and Environmental Management of the University of New Brunswick is gratefully acknowledged.

We thank Donnie McPhee, Kathleen Forbes, Laurie Yeates, January Bonga, and Tannis Beardmore of NRCan-CFS for their contribution.

${ }^{1}$ To whom reprint requests should be addressed; e-mail jloo@nrcan.gc.ca.
}

that the trees may be resistant to the beech scale rather than to the fungi because the Nectria fungi rarely cause damage in the absence of the scale (Houston and Houston 1994; Shigo, 1964; Wainhouse et al., 1988). Studies have shown that when challenged, grafted scions from putatively resistant trees retain resistance to the scale insect 1 year after inoculation with scale eggs. In the same study, the scale successfully reproduced only on clones grafted from known susceptible trees giving an indication of genetic resistance (Ramirez, 2005). If genetic resistance exists in natural populations, restoration of disease-free beech in North American forests may be possible through vegetative propagation of resistant trees.

Conventional vegetative propagation of species in the genus Fagus is difficult and has not been successfully achieved on a commercial scale (Chalupa, 1996; Meier and Reuther, 1994). Positive results in terms of low contamination, high shoot initiation, and rooting have been obtained using material from juvenile plants (Chalupa, 1985; Meier and Reuther, 1994; Viéitez et al., 1993); however, successful transfer to soil of the plantlets obtained has not been reported, and this is a major limitation to conventional propagation of Fagus species.

Micropropagation of $F$. grandifolia has had little success in the transfer of rooted plantlets from culture conditions to soil (Barker et al., 1997; Simpson, 2001). Barker et al. (1997) identified a suitable culture medium and were able to root material using LC-1 Horticubes (Smithers-Oasis Co., Kent, Ohio). Simpson (2001) cultured buds from mature trees and encountered problems with contamination of in vitro cultures and rooting. He succeeded in transferring some plantlets to a nonsterile growing medium, but none survived through winter. Grafting success of American beech has not been reported, but European beech ( $F$. sylvatica) has been grafted with $25 \%$ to $30 \%$ success (Dirr and Heuser, 1987).

The purpose of this study was to further the development of vegetative propagation techniques for disease-free American beech, including tissue culture and grafting. This was done by:

1. Experimenting with techniques to decrease in vitro contamination, increase rooting success, and acclimatize plantlets to greenhouse conditions; and

2. Determining factors that contribute to the success or failure of grafts.

\section{Materials and Methods}

Study area. Material for this study was collected from 12 locations in southern New Brunswick (Fig. 1). Thirty-nine putatively resistant and seven diseased trees were selected, and a subsample of these was used for each propagation method. The selected trees were at least $15 \mathrm{~cm}$ in diameter at breast height (DBH) and were deemed putatively resistant if they had no visible signs of BBD (scale insect, cankers, or Nectria fruiting bodies). It was assumed that the different trees are genetically distinct from each other because they were at least $100 \mathrm{~m}$ apart, although there is no definite proof of that.

Micropropagation from buds. Branches containing dormant buds were collected in Feb. 2003 and 2004 from 22 disease-free trees. The branches were stored in waterfilled buckets in the dark at $4{ }^{\circ} \mathrm{C}$ before they were used $(\approx 4$ weeks).

In 2003, 80 apical buds were taken from each tree and, in sets of 10 , surface sterilized for $5 \mathrm{~min}$ with $150 \mathrm{~mL}$ of $5.25 \%$ sodium hypochlorite containing three drops of antibacterial detergent followed by three rinses in sterile water. Bud scales were excised, and each bud was placed in a $150 \times 18-\mathrm{mm}$ Pyrex test tube containing $12 \mathrm{~mL}$ of Aspen Culture Medium (ACM) (Ahuja, 1984) supplemented with $0.89 \mu \mathrm{M}$ 6-benzyladenine (BA), 0.27 $\mu \mathrm{M} \alpha$-naphthalene acetic acid, $20 \mathrm{~g} \cdot \mathrm{L}^{-1}$ sucrose, and $7 \mathrm{~g} \cdot \mathrm{L}^{-1}$ agar as described by Barker et al. (1997). Cultures were incubated in a growth room at constant temperature of $26^{\circ} \mathrm{C}$ with a 16 -h photoperiod under fluorescent light $\left(55 \mu \mathrm{mol} \cdot \mathrm{m}^{-2} \cdot \mathrm{s}^{-1}\right)$. Explants were transferred to freshly prepared medium every 3 weeks. After 6 weeks, shoots initiated from each bud were excised and transferred to the elongation medium (ACM with half-strength plant growth regulators). When the height of explants reached $3 \mathrm{~cm}$, they were removed from the medium and dipped in $12.3 \mathrm{nM}$ nonsalt indolebutyric acid (IBA) for $1 \mathrm{~min}$ 


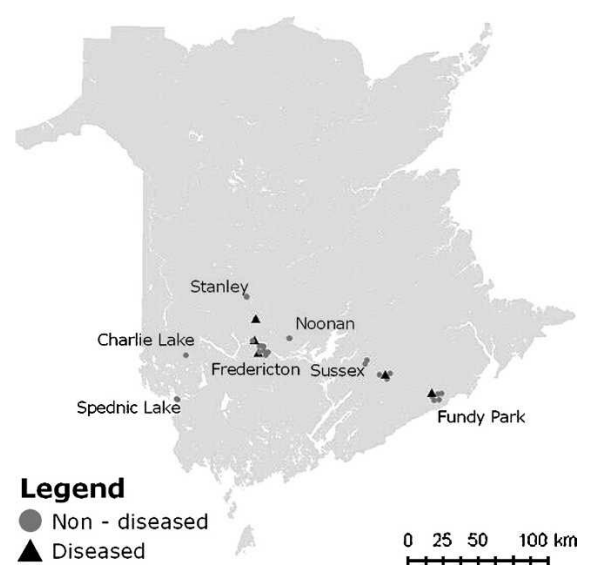

Fig. 1. Location of New Brunswick sites where material was collected from diseased and nondiseased American beech for vegetative propagation.

and transferred into LC-1 Horticubes (Smithers-Oasis Co., Kent, Ohio) saturated with half-strength liquid ACM and placed in a sterile Magenta GA7 vessel for rooting. The Magenta vessels were then placed in a growth room (conditions as stated previously). Rooted plantlets were transferred to $6 \times 6 \times 6-\mathrm{cm}$ pots containing a sterile mixture of peatmoss and vermiculite $(2: 1)$, sprayed with benomyl (Benlate, DuPont, Wilmington, Del.) $(2 \mathrm{~g} / \mathrm{L})$ to avoid fungal contamination, and saturated with distilled water to which $35 \mathrm{ppm}$ of $8 \mathrm{~N}-20 \mathrm{P}-30 \mathrm{~K}$ fertilizer was added. The pots were individually enclosed in plastic bags and placed on a growth bench with the same light conditions as in the growth room. Over a period of 4 weeks, the bags were gradually opened to allow progressive acclimatization; the photoperiod was gradually reduced to $12 \mathrm{~h}$ to induce bud set. When buds formed, the pots were placed in a greenhouse to overwinter at $4{ }^{\circ} \mathrm{C}$.

In 2004, two sterilization approaches were tested for 20 genotypes to reduce the high contamination of cultures experienced in 2003. The sterilization method applied in 2003 became a reference (control) applied to only 20 buds per genotype. In the first treatment, 30 buds per genotype were surfacesterilized using $150 \mathrm{~mL}$ of $5.25 \%$ sodium hypochlorite containing three drops of antibacterial detergent (Palmolive, ColgatePalmolive, N.Y.) for $5 \mathrm{~min}$, then stirred in $75 \%$ alcohol for $5 \mathrm{~min}$, and rinsed in sterile water. In the second treatment, 30 buds per genotype were surface sterilized using $150 \mathrm{~mL}$ of $5.25 \%$ sodium hypochlorite containing three drops of antibacterial detergent for $5 \mathrm{~min}$ followed by three rinses in sterile water. Bud scales were then removed and bud contents were sterilized in $1 \%$ sodium hypochlorite for $20 \mathrm{~min}$ followed by three rinses in sterile water. The culture media and culture environment were the same as described for 2003.

Contaminated cultures were counted and a contamination percentage was calculated for each genotype. Percentage of contamination in vitro was analyzed according to a randomized block design using treatment (alcohol, resterilization, or control) as a fixed factor and genotype as a random factor (block). For all trials in this study, analysis of variance was conducted using the General Linear Models (GLM) procedure of SAS 8.2 (SAS Institute, Cary, N.C.). Residuals were tested for departure from normal distribution using the univariate procedure of SAS. When data were not distributed normally because of the presence of zeros, they were transformed by $\log (\mathrm{x}+1)$. Arcsine $(\sqrt{ } \mathrm{x})$ transformation was used for percentages. Tukey's test was used for post hoc comparisons of means.

To improve rooting of cultured shoots, in 2004, half the explants per genotype that reached $3 \mathrm{~cm}$ (only 12 genotypes had explants that reached $3 \mathrm{~cm}$ ) were placed in the dark at room temperature for $7 \mathrm{~d}$ before rooting. Explants with roots longer than 5 $\mathrm{mm}$ were classified as rooted, and a rooting percentage was calculated for each genotype. The number of rooted explants that reached $3 \mathrm{~cm}$ in height varied per genotype. Rooting success was analyzed according to a randomized block design using treatment (dark period or control) as a fixed factor and genotype as a random factor (block).

Root sprouts. Root segments $(\approx 0.5 \mathrm{~m}$ long) 1 to $4 \mathrm{~cm}$ in diameter, totaling $3 \mathrm{~m}$ in length, were collected in May 2004 from 13 nondiseased, mature trees. The segments were placed in trays (two trays per genotype) and covered with moist peat. Small incisions were made in the bark and cambium to induce callusing. Half of the roots from each genotype were sprayed with $50 \mathrm{mg}$ of BA dissolved in $100 \mathrm{~mL}$ of $50 \%$ ethanol. The number of sprouts per meter of root was determined for each genotype and analyzed according to a randomized block design using treatment (IBA or control) as a fixed factor and genotype as a random factor (block). Most (145) of the resulting root sprouts were used as a source of shoot tips ( $3 \mathrm{~cm}$ long) for micropropagation in vitro. The shoot tips came from 13 genotypes, but the number of shoots per genotype varied. The shoot tips were surface-sterilized in $0.5 \%$ sodium hypochlorite for $15 \mathrm{~min}$, rinsed with sterile water, and then cultured in vitro as described for dormant buds.

Grafting. Scions were collected in late February and early March 2003 and 2004 from putatively resistant and diseased trees. Twigs (20-25 cm long) with two to three buds were cut from branches, packed into plastic bags containing snow, brought to the research facility, and stored at $0{ }^{\circ} \mathrm{C}$ for no more than $2 \mathrm{~d}$ before grafting. The rootstock grown from seeds collected from open-pollinated trees was potted in a mixture of 2 peatmoss : 2 perlite : 1 aggregate (small rock) : 1 loam. The grafting technique was top cleft matching the cambium of the scion closely with that of the rootstock. Graft unions were wrapped with grafting rubber bands and coated with warm wax to hold the graft in place and prevent drying. Grafted plants were placed in a greenhouse under controlled conditions (initially, 70\% humidity, 16-h photoperiod, $10-12{ }^{\circ} \mathrm{C}$ for 3 weeks, then the temperature was increased gradually to match outdoor conditions). The grafts were assessed weekly for 15 weeks, and on the 15 th week, graft success was determined. Successful grafts were kept in the greenhouse for a total of 5 months and then placed in an outdoor shaded area.

A total of 22 putatively resistant and five diseased trees were selected for scion collections in 2003 and 2004. Twenty scions per tree were grafted onto 1-year-old rootstock in 2003 and a mixture of 1- and 2-year-old rootstock in 2004. The older rootstock was intended to improve matching diameter with that of the scions. In 2004, the cut surfaces of half of the scions were dipped in a $200 \mathrm{ppm}$ solution of IBA. The effect of IBA application and rootstock age on grafting success was analyzed according to a split-plot design with treatment (IBA or control) and age (1 or 2 years old) as fixed factors and genotype as a random factor.

In 2005, 19 new trees (two diseased and 17 putatively resistant) were selected for scion collection. Forty scions per genotype were grafted onto rootstock grown from seeds collected from open-pollinated trees (five disease-free and one diseased). The same proportion of each type of rootstock was used to graft each genotype. If the rootstock had a large diameter that did not match any of the scions, the side veneer grafting technique was used. Rootstock height and diameter, scion height, diameter and number of buds, length of graft union, and presence of callus were recorded when flushing stopped. Grafting success was analyzed separately by rootstock type, graft type, number of buds on the scion, length of the junction, length of scion, and rootstock and diameter category according to randomized block design. Four diameter categories were assigned to describe differences between scion and rootstock: $\mathrm{I}=$ scions with a diameter larger than that of the rootstock $(>0.5 \mathrm{~mm})$, II $=$ close match (difference in diameters $<0.5$ $\mathrm{mm}), \mathrm{III}=$ rootstock with a diameter larger than that of the scion $(>0.5 \mathrm{~mm})$, and IV $=$ much larger rootstock $(>1.5 \mathrm{~mm})$.

\section{Results}

Micropropagation from buds. Cultured buds from mature trees elongated very slowly. In some cases, a distinct stem developed first, whereas in other cases, the leaves developed first. In 2003, all genotypes were micropropagated with the exception of one in which only reproductive organs were found after bud scale removal. During the initiation period (first 6-10 weeks), contamination significantly reduced the number of explants remaining in culture to $17 \%$ to $98 \%$ of the cultured buds per genotype.

Resterilization and the alcohol treatment (Fig. 2) reduced the initial culture contamination in 2004, but only the difference between the control and the resterilization treatment was statistically significant (Table 1). Contamination also varied by 


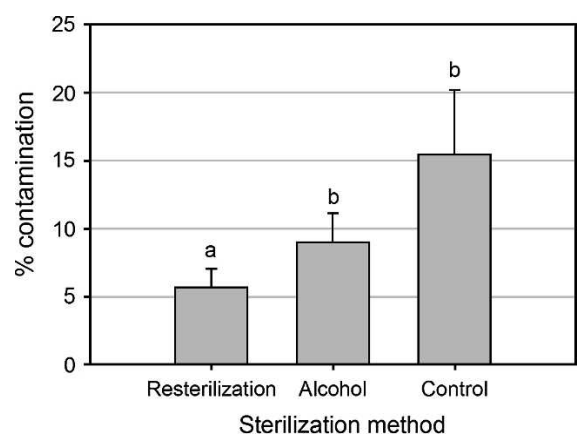

Fig. 2. Mean percentage of contamination $( \pm \mathrm{SE})$ $(n=20)$ after three sterilization techniques in tissue culture of American beech from dormant buds collected from mature trees. Means with a common letter are not different $(P \leq 0.05)$ by Tukey's post hoc comparison of means.

genotype. Buds from three of the 15 source trees had less contamination after the alcohol treatment.

In 2003, one to 2.7 new shoots were initiated per explant. Explants grew in the elongation medium 8 to 10 weeks, and only 16 genotypes $(76 \%)$ produced shoots suitable for transferring into the rooting medium. After 5 to 14 weeks in the rooting medium, seven genotypes $(44 \%)$ produced rooted explants with $10 \%$ to $60 \%$ rooted explants per genotype. In 2004, rooting of explants increased significantly $(P=0.003)$ with the application of a 7-d dark period (Fig. 3). Rooting increased for all but two genotypes, which did not produce roots with either method. All rooted explants were successfully transferred to soil and produced buds in the ex vitro environment.

In the spring, none of the plantlets flushed when exposed to conditions that should have promoted bud burst. Buds appeared to be empty, containing no preformed leaves. It appeared that bud development stopped after the formation of the bud scales.

Root sprouts. All selected genotypes produced sprouts from root segments in 6 to 10 weeks. Sprouts formed mainly in clusters extending from the cut ends of the roots. The application of BA to the surface of the roots significantly $(P=0.001)$ increased the number of sprouts per meter of root (Fig. 4, Table 1). Only one genotype did not produce sprouts with the hormone spray but did produce sprouts without it.

Table 1. Results of analysis of variance on percentages of contamination and rooting in tissue culture of American beech from dormant buds.

\begin{tabular}{lrcrc}
\hline Sources of variation & df & MS & F & $P$ \\
\hline Percent contamination & & & & \\
$\quad$ Treatment & 2 & 0.1260 & 3.91 & 0.028 \\
$\quad$ Genotype & 19 & 0.0797 & 2.47 & 0.009 \\
$\quad$ Error & 38 & 0.0322 & & \\
Percent rooting & & & & \\
$\quad$ Treatment & 1 & 2.6872 & 14.99 & 0.003 \\
$\quad$ Genotype & 11 & 0.1831 & 1.02 & 0.486 \\
$\quad$ Error & 23 & 0.1793 & & \\
\hline
\end{tabular}

df, degrees of freedom; MS, mean square.

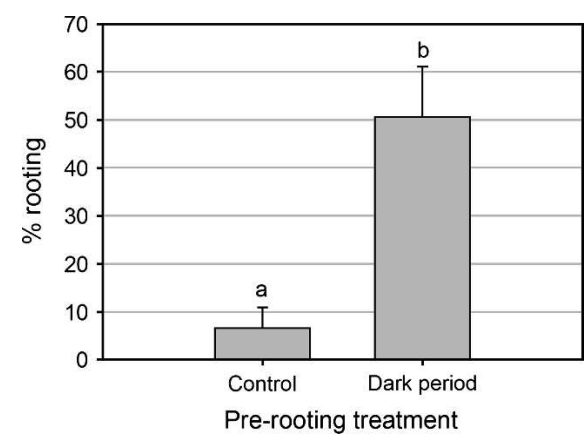

Fig. 3. Mean percentage of rooting $( \pm \mathrm{SE})(\mathrm{n}=12)$ after two prerooting treatments in tissue culture of American beech from dormant buds collected from mature trees. Means with a common letter are not different $(P \leq 0.05)$.

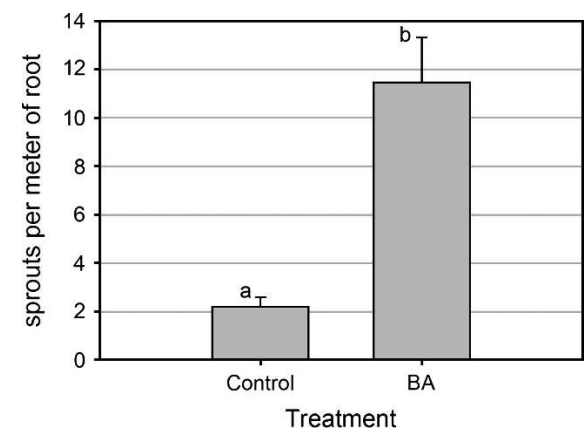

Fig. 4. Mean number of sprouts per meter of root $( \pm \mathrm{SE})(\mathrm{n}=13)$ collected from mature American beech trees placed under growth promoting conditions and treated or not (control) with a BA spray. Means with a common letter are not different $(P \leq 0.05)$.

The shoot tips collected from root sprouts and cultured in vitro had low contamination $(19 \%)$, but rooting succeeded in only five genotypes $(38 \%)$ and in these genotypes, it ranged from $14 \%$ to $57 \%$. None of the plantlets successfully overwintered in the greenhouse.

Grafting. In 2003, the overall graft survival was $30 \%$ and all genotypes had some successful grafts. In 2004, grafting success was only $12 \%$ with $84 \%$ of represented genotypes producing some successful grafts. Most genotypes (88\%) produced more successful grafts in 2003 than in 2004. Success varied by genotype, and there was no significant difference in grafting success between putatively resistant and diseased phenotypes. In 2004, scions treated with IBA had slightly lower success $(10.4 \%)$ than the untreated scions $(14.4 \%)$. Grafts on 2-year-old rootstock had better survival $(14.8 \%)$ than those on 1-year-old rootstock (10\%) (Fig. 5). However, these differences were not statistically significant (Table 3). There were no significant interaction effects between rootstock age and plant growth regulator treatment or between treatment and genotype. There was a significant interaction between rootstock age and genotype (Table 3); however, it was incited by $20 \%$ of the genotypes having better
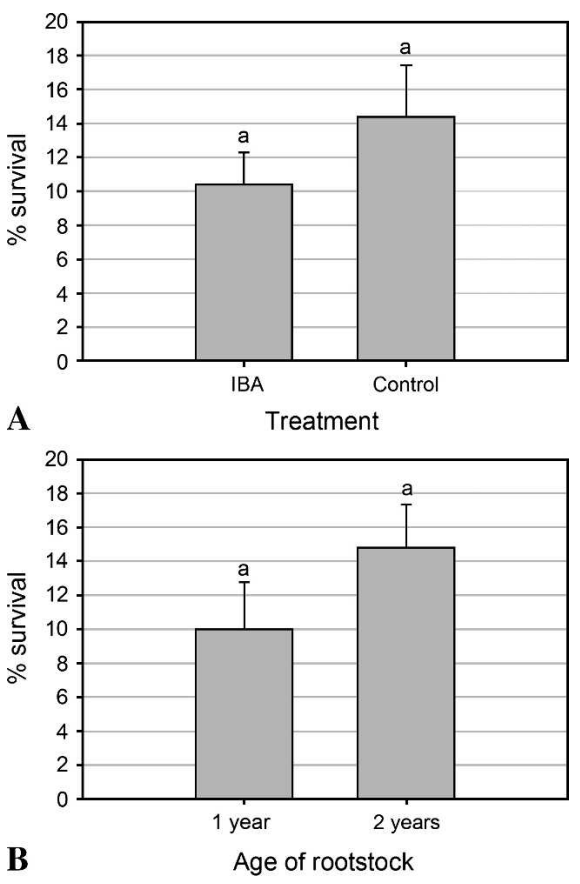

Fig. 5. (A) Mean percentage survival of grafts of American beech $( \pm \mathrm{SE})(\mathrm{n}=24)$ after a dipping treatment of the scion in 200 ppm IBA versus an untreated control. (B) Survival of grafts made onto 1- or 2-year-old rootstock. Means with a common letter are not different $(P \leq$ $0.05)$.

grafting success on 1-year-old rootstock, whereas the rest had greater success on the 2-year-old rootstock.

In 2005 , overall grafting success was $18 \%$ and varied by genotype. Of 19 genotypes, 17 produced successful grafts with success ranging from $5 \%$ to $50 \%$ per genotype. Callus formed on $57 \%$ of the grafts, but only $32 \%$ of those grafts survived. In all unsuccessful grafts, callus developed only on the rootstock. Rootstock origin had a significant effect on grafting success. Rootstock obtained from seeds of one tree (\#1192) had significantly better graft survival $(25 \%)$ than rootstock from tree \#1197 (10\%). Tree \#1192 was asymptomatic, whereas tree \#1197 was diseased. All other rootstock origins were not significantly different from each other. Only $7 \%$ of the grafts were made using the side veneer technique, and the rate of success $(18 \%)$ was not significantly different from the top cleft grafts. The number of buds present on the scion affected grafting success. The success of scions with two buds (29\%) was significantly better than of those with three and four buds ( $18 \%$ and $11 \%$, respectively).

The difference between diameters of the rootstock and scion for top cleft grafts had a significant effect on grafting success, depending on whether the scion diameter was larger, similar, or smaller than the rootstock diameter.

The best grafting success $(72 \%)$ occurred when the scion diameter was $>0.5 \mathrm{~mm}$ larger than the rootstock diameter (category I). This was significantly different from all other diameter match categories (Fig. 6, Table 4). 
Table 2. Results of analysis of variance on number of sprouts per meter of root collected from mature American beech trees comparing two treatments (BA spray or control).

\begin{tabular}{lrcrc}
\hline Sources of variation & df & MS & \multicolumn{1}{c}{ F } & $P$ \\
\hline Treatment & 1 & 9.9684 & 23.54 & 0.000 \\
Genotype & 12 & 0.6725 & 1.59 & 0.217 \\
Error & 12 & 0.4235 & & \\
\hline
\end{tabular}

df, degrees of freedom; MS, mean square.

The length of the union between scion and rootstock was also a determining factor in grafting success. Junctions shorter than 2.5 $\mathrm{cm}$ had significantly less success $(10 \%)$ than those longer than $2.5 \mathrm{~cm}(31 \%)$. Scion length had no significant effect on success; however, rootstock length did. Short rootstock $(<10$ $\mathrm{cm})$ had greater success $(21 \%)$ than long rootstock $(13 \%)$.

\section{Discussion}

Micropropagation. Studies on micropropagation of American beech have encountered many common difficulties, including high initial contamination of tissue cultures, low rooting success, and failure to establish cultures in the soil (Barker et al., 1997; Simpson, 2001; K. Ellis, unpublished data).

Contamination can be reduced by resterilizing the buds after removing bud scales. This way, pathogens located inside the bud scales,

Table 3. Results of analysis of variance on percentage of grafting success in American beech scions collected from various genotypes $(\mathrm{G})$ comparing effects of rootstock age (A) (1 or 2 years old) and hormonal treatment (T) (a dip in 200 ppm IBA).

\begin{tabular}{lrccc}
\hline Source of variation & df & MS & F & $P$ \\
\hline G & 23 & 394.4 & 3.05 & 0.607 \\
$\mathrm{~T}$ & 1 & 402.9 & 3.12 & 0.213 \\
$\mathrm{~A}$ & 1 & 551.0 & 4.27 & 0.206 \\
$\mathrm{G} \times \mathrm{T}$ & 23 & 245.4 & 1.90 & 0.065 \\
$\mathrm{G} \times \mathrm{A}$ & 23 & 325.9 & 2.52 & 0.015 \\
$\mathrm{~T} \times \mathrm{A}$ & 1 & 277.9 & 2.15 & 0.156 \\
Error & 23 & 129.1 & & \\
\hline
\end{tabular}

df, degrees of freedom; MS, mean square.

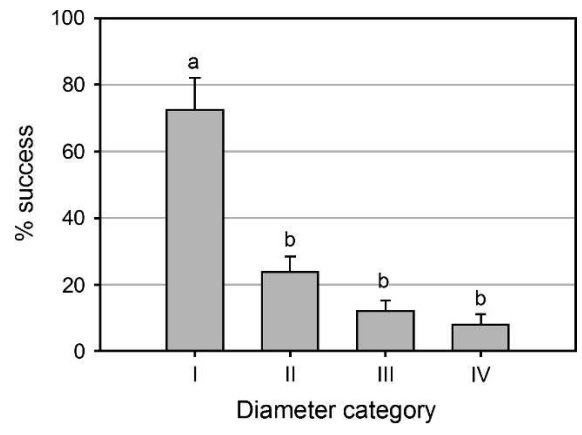

Fig. 6. Mean grafting success $( \pm \mathrm{SE})(\mathrm{n}=18)$ for different diameter categories of American beech grafts. I) larger scions $(>0.5 \mathrm{~mm})$, II) close match (difference in diameters $<0.5 \mathrm{~mm}$ ), III) larger rootstock $(>0.5 \mathrm{~mm})$, IV) larger rootstock $(>1.5 \mathrm{~mm})$. Means with a common letter are not different $(P \leq 0.05)$ by Tukey's post hoc comparison of means.

Table 4. Results of analysis of variance on percentage of grafting success in American beech comparing effects of rootstock origin, graft type (top cleft or side veneer), number of buds on the scion $(2,3$, or 4), matching diameters (categories I, II, III, or IV), union length $(<2.5 \mathrm{~cm}$ or $>2.5 \mathrm{~cm})$, scion length $(<15 \mathrm{~cm}$ or $>15 \mathrm{~cm})$, and rootstock length $(<10 \mathrm{~cm}$ or $>10 \mathrm{~cm})$.

\begin{tabular}{|c|c|c|c|c|}
\hline Sources of variation & df & MS & $\mathrm{F}$ & $P$ \\
\hline Rootstock origin & 5 & 663.8 & 3.01 & 0.015 \\
\hline Genotype & 18 & 1154.0 & 5.24 & $<0.001$ \\
\hline Error & 91 & 220.3 & & \\
\hline Graft type & 1 & 0.6 & 0.00 & 0.949 \\
\hline Genotype & 12 & 530.0 & 3.99 & 0.012 \\
\hline Error & 12 & 132.9 & & \\
\hline Number of buds & 2 & 1350.6 & 41.63 & $<0.001$ \\
\hline Genotype & 16 & 765.4 & 2.98 & 0.001 \\
\hline Error & 32 & 164.3 & & \\
\hline Diameter category & 3 & 3.3149 & 44.89 & $<0.001$ \\
\hline Genotype & 17 & 0.2371 & 2.23 & 0.039 \\
\hline Error & 51 & 0.0796 & & \\
\hline Union length & 1 & 3277.0 & 11.02 & 0.004 \\
\hline Genotype & 16 & 488.9 & 1.64 & 0.165 \\
\hline Error & 16 & 297.4 & & \\
\hline Scion length & 1 & 0.0382 & 3.14 & 0.093 \\
\hline Genotype & 18 & 0.0942 & 7.73 & $<0.001$ \\
\hline Error & 18 & 0.0122 & & \\
\hline Rootstock length & 1 & 0.1984 & 11.16 & 0.004 \\
\hline Genotype & 18 & 0.0948 & 5.34 & $<0.001$ \\
\hline Error & 18 & 0.0178 & & \\
\hline
\end{tabular}

df, degrees of freedom; MS, mean square.

can be eliminated without causing harm to the tissues intended for culturing (J.M. Bonga, per. comm., 2004).

In this study, a week-long dark period before inducing the rooting of in vitro cultured shoots enhanced rooting in cultures derived from mature and juvenile material. The dark treatment also improved rooting capacity and accelerated root emergence in F. sylvatica (Viéitez et al., 1993). In contrast, Barker et al. (1997) had only 3\% rooting success with juvenile material of American beech despite applying a dark period and including IBA in the rooting media. The same authors found the highest rooting and plantlet survival using Horticubes and liquid ACM without IBA but did not report this method in combination with a dark period. Tissue culture often uses dark treatment, although it is not well understood why this treatment enhances rooting in vitro.

When transferring cultures into the soil, individual plastic enclosures provided an adequate environment for the explants to adjust to the nonsterile and less humid conditions. Simpson (2001) tested different approaches to acclimatization, including placing individual plastic bags and clear plastic containers over rooted plantlets; however, none of these methods succeeded. Allowing explants more time to grow in soil before bud set occurs may help to overcome the problem of nonsurvival after overwintering. Unfortunately, many plantlets initiate buds soon after being removed from in vitro conditions. More cultural approaches should be studied with the aim of extending the period of growth before bud set as well as providing adequate conditions for completion of bud development.

Micropropagation of Fagus is typically more successful from juvenile material than from mature material (Barker et al., 1997; Chalupa, 1996; Viéitez et al., 1993). Unfortunately, because juvenile material was not available for this study in sufficient quantities, it was necessary to use tissues from mature trees for propagation. Presently, the most reliable way to identify putatively resistant trees is to survey forest stands for scale-free mature trees. We attempted to rejuvenate material for propagation by using young root sprouts from older roots. Simpson (2001) used root sprouts as cuttings and on average obtained 2.3 sprouts per meter of root length using a technique similar to the one tested in this study but without the BA treatment. We found that applying BA to the roots increased production of root sprouts (11.4 sprouts per meter of roots versus 2.2 without BA). Although micropropagated root sprouts were easier to sterilize than dormant buds, they produced no more roots than did cultures from buds. This suggests that rejuvenation was not achieved by inducing root sprouts or that maturity was not the main problem preventing rooting of cultured organs.

Grafting. Grafting was the only successful propagation technique, although the rate of success was low. Dirr and Heuser (1987) mentioned that Fagus spp. were very difficult to graft and reported $25 \%$ to $30 \%$ grafting success for $F$. sylvatica, which is similar to the results we obtained in 2003.

The short period of exposure to cool temperatures for the 2004 grafts may have contributed to the low grafting success in that year. Many authors recommend that grafts should be kept under cool temperatures (13$18^{\circ} \mathrm{C}$ ) for at least the first 3 weeks to slow down the flushing of buds (Dirr and Heuser, 1987; Hallett et al., 1981). In 2004, grafts were placed in warm conditions $\left(25^{\circ} \mathrm{C}\right)$ after 1 week of cool temperatures. 
A successful graft union depends on the formation of a callus bridge between the cut surfaces of the scion and rootstock (Macdonald, 1986). The application of a growth regulator (e.g., IBA) stimulates cell division in the scion callus and accelerates the restoration of vascular connections (Cummings, 1997). For unknown reasons, IBA did not improve success in the 2004 grafting trial. Observations in 2005, which show that many of the unsuccessful grafts had callus formed on the rootstock but not on the scion, suggest a potential incompatibility between the scion and the rootstock. It is possible that matching the scions with rootstock produced from seed collected from the same tree will reduce the incompatibility and improve overall grafting success of American beech.

When grafting in winter, it is difficult to select good-quality rootstock from dormant seedlings. Based on work with $F$. sylvatica, Savill et al. (2005) concluded that rootstock quality was critical to the success of grafting. Two-year-old rootstock is typically more reliable than that of younger and smaller plants (Douglas, 1999). In our study, rootstock age did not affect grafting success. It is possible that the quality of our 2-year-old rootstock was not optimal because it was stored in an outdoor overwintering house and subjected to repeated thawing and freezing (L.D. Yeates, per. comm., 2005), whereas 1 -year-old rootstock was stored indoors.

In 2005, the factors that most limited grafting success were the origin and subsequent storage treatment of rootstock, the number of buds on the scion, the difference in diameters between scion and rootstock, the length of the junction, and the length of the rootstock. Many authors recommend that, for grafting, the stock material should be free of diseases (Dirr and Heuser, 1987; Hartman and Kester, 1975; Procketer, 1976). In our study, scions grafted on rootstock that originated from seed from a diseased tree had the lowest success compared with a nondiseased seed source. Grafts with larger junctions had more area to match the cambium of scion and rootstock and, therefore, had better success. The difference between diameters of rootstock and scion may be critical in grafting beech. In this study, grafts with scion diameters larger than the rootstock had better success. Grafting literature recommends that, for grafting small-diameter scions and rootstock, best results are obtained when the diameters are similar (Dirr and Heuser, 1987; Fretz et al., 1979). There are no reports of increased success with slightly larger scions.

Overall, grafting was the only method of propagation that reliably produced some successful plants, but its efficiency is unsatisfactory. Only modest advances in tissue culture of American beech were achieved in this study. In the culture from dormant buds, the contamination problem, troublesome in all reported studies, was substantially reduced and higher in vitro rooting percentages were obtained. Further refinement of the earlier steps may improve the efficiency of producing rooted plantlets. However, the reality is that despite success in producing some rooted plantlets transferable to nonsterile culture, not a single plantlet, produced in vitro, survived under nonsterile conditions. The causes of failure remain unknown, and until they are identified, the manipulation of growth conditions at this stage remains guesswork.

\section{Literature Cited}

Ahuja, M.R. 1984. In vitro induction of organogenesis in juvenile and mature beech. Silvae Genet. 33:131-135.

Barker, M.J., P.M. Pijut, M.E. Ostry, and D.R. Houston. 1997. Micropropagation of juvenile and mature American beech. Plant Cell Tissue Org. Cult. 52:209-213.

Chalupa, V. 1985. In vitro propagation of Larix, Picea, Pinus, Quercus, Fagus and other species using adenine-type cytokinins and thidiazuron. Commun. Inst. For. Cech. 14:65-90.

Chalupa, V. 1996. Fagus sylvatica L. (European beech), p. 138-154. In: Bajaj, Y.P.S. (ed.). Biotechnology in agriculture and forestry, Vol 35, Trees IV. Berlin, Heidelberg.

Cummings, J.N. 1997. Rooting hormones may increase grafting results. Pomona 32:33-34. (North American Fruit Explorers).

Dirr, M.A. and C.W. Heuser. 1987. The reference manual of woody plant propagation. From seed to tissue culture. Varsity Press, Athens, Ga.

Douglas, G.C. 1999. Advanced and conventional methods for vegetative propagation of selected lines of oak and cherry. Kinsealy Research
Centre. Horticulture and Farm Forestry Series No. 8. Dublin.

Fretz, T.A., P.E. Read, and M.C. Peele. 1979. Plant propagation lab manual. Burgess Pub. Co., Minneapolis, Minn.

Hallett, R.D., R.F. Smith, and T.W. Burns. 1981 Manual for greenhouse grafting of conifers in the Maritimes. Inform. Rep. M-X-117E. Natural Resources Canada, Canadian Forest Service-Atlantic Forestry Centre, Fredericton, N.B.

Hartman, H.T. and D.E. Kester. 1975. Plant propagation; principles and practices. Prentice-Hall, Englewood Cliffs, N.J.

Houston, D.R. 1980. Beech bark disease: What we do and do not know. Ann. Sci. For. 37: 269-274.

Houston, D.B. and D.R. Houston. 1994. Variation in American beech (Fagus grandifolia Ehrh.): Isosyme analysis of genetic structure in selected stands. Silvae Genet. 43:277-284.

Macdonald, B. 1986. Practical woody plant propagation for nursery growers. Timber Press Inc., Portland, Ore.

Meier, K. and G. Reuther. 1994. Factors controlling micropropagation of mature Fagus sylvatica. Plant Cell Tiss. Org. Cult. 39:231-238.

Procketer, N.J. 1976. Simple propagation: A book of instructions for propagation by seed, division, layering, cuttings, budding and grafting. Scribner, N.Y.

Ramirez, M. 2005. Screening for genetic resistance and vegetative propagation of disease-free American beech (Fagus grandifolia). M.Sc.F. Thesis, Univ. New Brunswick, Fredericton, NB, Canada.

Savill, P.S., J. Fennessy, and C.J. Samuel. 2005. Approaches in Great Britain and Ireland to the genetic improvement of broadleaved trees. Forestry 78:163-173.

Shigo, A.L. 1964. Organism interaction in the beech bark disease. Phytopathology 54: 263-269.

Simpson, J.I. 2001. Vegetative propagation of American beech (Fagus grandifolia). M.Sc.F. Thesis, Univ. New Brunswick, Fredericton, NB, Canada.

Viéitez, A.M., E.M. Ferro, and A. Ballester. 1993. Micropropagation of Fagus sylvatica L. In Vitro Cell. Dev. Biol. 29:183-188.

Wainhouse, D., I.M. Gate, and D. Lonsdale. 1988 Beech resistance to the beech scale: A variety of defenses, p. 277-293. In: W.J. Mattson, J. Levieux, and C. Bernard-Dagan (eds.), Mechanisms of woody plant defenses against insects: Search for pattern Proc. IUFRO WP Symposium, Orléans, France, 26-29 Aug. 1986. Springer-Verlag, N.Y. 